\title{
Reducing Inequality - The Missing MDG: A Content Review of PRSPs and Bilateral Donor Policy Statements
}

\author{
Sakiko Fukuda-Parr*
}

\begin{abstract}
Although important gains have been made in reducing global poverty, the pace of progress across the world is not on track to achieve the 2015 MDG targets. Is this due to lack of ownership on the part of national governments and the international community? This article examines whether the Poverty Reduction Strategy Papers (PRSPs) and donor policy statements are aligned with MDG priorities and targets. The analysis found a high degree of commitment to MDGs as a whole but both PRSPs and donor statements are selective, consistently emphasising income poverty and social investments for education, health and water but not other targets concerned with empowerment and inclusion of the most vulnerable such as gender violence or women's political representation. The article concludes that a new, ninth Goal needs to be added - to reduce inequality - to make the MDGs aligned to the original purpose of the Millennium Declaration.
\end{abstract}

\begin{abstract}
1 Introduction
The Millennium Development Goals (MDGs)

have received unprecedented political commitment and forged a strong consensus on poverty eradication as the primary objective of international development efforts. Yet implementation lags and recent trends for most of the Indicators show progress needs to be dramatically speeded up to meet the 2015 Targets (UN 2007; World Bank 2008). These gaps raise questions about weak commitment or ownership, especially by developing country policymakers who may place growth ahead of poverty reduction in their priorities, and by donor institutions which may not agree to financing ambitious goals (Martin and Stever 2007).
\end{abstract}

The purpose of this article is to explore this issue of 'ownership' by examining the extent to which national development strategies and donor policies are aligned with MDG priorities and Targets. The article analyses the Poverty Reduction Strategy Papers (PRSPs) of 22 countries and development cooperation policy statements of 21 bilateral aid programmes.
Assessing alignment with MDG priorities and Targets is not straightforward. At one level, the Goals can be mechanistically incorporated into PRSPs and donor policy statements as planning targets and guide resource allocations. But that raises a question of how and whether these globally set Goals are to be integrated into national priorities and processes. At another level, MDGs could be considered to be broad long-term objectives that should guide general priority setting. That raises questions about how the Goals can be implemented. Finally, should alignment be with the MDGs or with the Millennium Declaration and the UN Development Agenda? Answering these questions requires making assumptions about what global goals are as tools of national economic management and of global governance.

The article starts with addressing these conceptual issues, then goes on in sections 2 and 3 to present an analysis of the PRSPs and the donor policy documents. Section 4 concludes with suggestions for strengthening the links between global goals and national policymaking, and attending to the neglected priorities. 


\section{Integrating MDGs into national policy: conceptual considerations}

It should be remembered that MDGs are structured as eight Goals, 34 Targets and 60 Indicators. It is the Targets and Indicators that are quantified and time-bound and receive the most attention. Numeric Indicators are intended to capture the essential aspects of changes in the social world that are desired. Development Indicators are not ends in themselves but are devices that help describe these ends in concrete terms. World leaders adopted the Millennium Declaration, and made a commitment: 'We will spare no effort to free our fellow men, women and children from the abject and dehumanizing conditions of extreme poverty, to which more than a billion of them are currently subjected'. Moreover, these commitments were part of the broader commitment to principles of equality, tolerance, solidarity, and to address four key global challenges, namely development and poverty reduction, peace and security, democracy and human rights, and environmental sustainability. These challenges are complex. Progress in implementing the commitments are difficult without the help of tangible 'Indicators' of progress.

Thus although each of the eight Goals and Targets are important, the significance of the MDGs lies in the package, representing global poverty in its multiple dimensions, and as an interrelated part of the four global challenges. According to the United Nations Development Programme (UNDP), ${ }^{1}$ the MDGs 'synthesise, in a single package, many of the most important commitments made separately at the international conferences and summits of the 1990s; recognise explicitly the interdependence between growth, poverty reduction and sustainable development; acknowledge that development rests on the foundations of democratic governance, the rule of law, respect for human rights and peace and security'.

\subsection{MDGs in context: the UN development agenda}

The MDGs are derived from the 2000

Millennium Declaration and developed in the implementation document, the 'Road Map' (UN 2001) presented by the UN Secretary-General to the General Assembly. But these in turn originated in the goals adopted by the global conferences of the 1990s on key development issues from environment to gender to human rights to habitat. The agendas were driven by a political process that was unprecedentedly participative, that involved civil society groups engaging in developing national positions, and in negotiating the global declaration, and an extended process of national, regional and global debates (Jolly et al. 2004; UN DESA 2007).

The agenda adopted at these conferences also reflect a consensus among a diversity of views on contentious issues of the $1990 \mathrm{~s}^{2}$ such as: the neoliberal agenda of economic globalisation; the opposition to the Washington Consensus; the concern with marginalisation of poor and weak countries; the demands of women for their rights in areas such as reproductive health; the protests of indigenous people over destruction of their livelihoods; the concerns of emerging economies over the instability of global financial markets; and the protests over the TRIPS agreement making access to medicines unaffordable. The agendas can be summed up as 'inclusive globalisation' for human development, acknowledging the benefits of globalisation but demanding that these benefits be more widely shared. They also focus on the human dimensions of development, and empowerment of people as both an end of and a means to development.

The UN refers to this set of agendas emanating from the 34 summits and conferences held up to 2005 as the 'UN Development Agenda', and the goals adopted, Internationally Agreed Development Goals (IADGs). The Agenda, like the Declaration, is embedded in the ethical values and fundamental purpose of the UN, namely human freedom and dignity, solidarity and burden sharing, equality and tolerance. As Ocampo writes in the Preface to The United Nations Development Agenda: Development for All (UN DESA 2007: iii), 'Two elements have permeated the content and character of the Agenda since its inception. First is a fundamental concern for equity and for equality of all persons, as human beings and as citizens ... [and] the second essential element: partnership. The conference process has engaged all the key stakeholders: governments, United Nations system organizations, other intergovernmental and non-governmental organizations, civil society, and the private sector'.

It should be noted that MDGs are weak in precisely these areas, leaving out issues of inequality except gender equality in primary 
school enrolment, democratic governance and participation (Nelson 2007; Saith 2006; OHCHR 2008), and systemic issues of global economic governance (Bissio 2003; Nelson 2007).

\subsection{Global goals as instruments in development planning and policy}

The UN has used goal setting as a tool for drawing attention and mobilisation to address neglected global challenges. Numeric Goals can be instrumental in three different ways:

As normative objectives that define long-term visions. Goals mobilise support and help forge consensus as the numeric Targets make the destination clear and concrete

- As evaluative benchmarks against which progress can be measured. Benchmarks are essential in monitoring progress necessary to enforce implementation and hold responsible parties accountable

- As planning targets applied to setting priorities for policy and resource allocation, and can be used by planners in government and in donor, especially financing agencies.

The designers used MDGs as normative objectives, to build consensus among world leaders at the Millennium Summit, and to provide benchmarks for monitoring implementation. ${ }^{3}$ However, it is less clear whether or how they were ever intended to be used in national planning or by donors. While the original conference declarations from which some Targets are drawn, such as the Children's Summit, and the Jomtien may adapt the Goals to specific national conditions in developing national implementation strategies, neither the Millennium Declaration nor the Road Map mention the issue.

Applying globally set quantitative Goals as national planning Targets raises a number of contradictions. As a 'one-size-fits-all' formula, it contradicts the respect for local priorities and processes that are widely recognised as necessary for implementation in the MDG discourse. Different countries have different possibilities, constraints and priorities. Some Goals are set too low for some countries where they have been reached. Some countries face priority challenges such as diseases that are not included among the MDGs. Planning on the basis of MDGs disrupts planning, programming and budgeting procedures of both recipient and donor countries. For example, even the categories do not overlap with national sectoral classifications.

Using MDGs as planning Targets also raises questions about their effectiveness; some have argued that this will require massive expansion of social expenditures financed by external aid which would backfire through undermining exchange rate and budget balances (Gupta $e t$ al. 2005). Others have questioned whether MDGs as a strategy will create growth and development momentum (Roy and Heurty 2005; Easterly 2006) and whether MDG achievement is feasible given institutional constraints (de Renzio 2005). Yet, others have raised concerns that the Goals are over-ambitious and may raise unrealistic expectations and undermine support for development aid (Clemens et al. 2007).

\section{Analysis of PRSPs}

PRSPs are statements of national strategy for poverty reduction that set out long-term objectives and priority actions. MDGs can be used as normative objectives, benchmarks or planning Targets.

Three aspects of implementation were analysed:

1 MDG priorities - which of and how strongly are the MDG priorities reflected in the PRSP priorities? Each PRSP was coded for policy commitment to an MDG agenda item as a priority; a strategic priority such as a 'pillar' or one of the several key objectives; whether there was a defined action plan; and whether quantitative outcome targets were defined.

2 Ambition of MDGs - are the PRSP quantitative targets in line with the ambition of the MDGs? A statistical analysis of the quantitative, time-bound targets in each of the PRSPs compared implied rate of progress with what it would take to achieve the Goals, and historical rates, assuming a linear progression to determine whether the PRSP targets were in line with, exceeded or undershot the MDG Targets and historical trends.

3 Millennium Declaration priorities - do the PRSPs reflect the broader Declaration objectives of inclusive globalisation and its broader ethical values of equality, participation and solidarity? 


\begin{tabular}{|c|c|c|c|}
\hline MDG priority & Action plan & $\begin{array}{l}\text { Pillar or core } \\
\text { objective }\end{array}$ & Targets defined \\
\hline \multicolumn{4}{|l|}{ Most included among PRSP priorities } \\
\hline Primary schooling - MDG 2 & 21 & 20 & 21 \\
\hline Health (general) - MDGs 4-6 & 20 & 19 & 20 \\
\hline Income poverty - MDG 1 & 18 & 15 & 21 \\
\hline Governance (rule of law, corruption) - MDG 5 & 18 & 11 & 3 \\
\hline Water and sanitation - MDG 7 & 18 & 6 & 21 \\
\hline Gender equality and empowerment (general) - MDG 3 & 16 & 4 & 8 \\
\hline HIV/AIDS and other diseases - MDG 6 & 15 & 7 & 17 \\
\hline Employment (general) - MDG 1 & 14 & 9 & 7 \\
\hline Hunger - MDG 1 & 14 & 2 & 1 \\
\hline Social integration and vulnerable groups - MDG 6 & 13 & 6 & 0 \\
\hline \multicolumn{4}{|l|}{ Least included among PRSP priorities } \\
\hline Employment in decent work - MDG 1 & 4 & 0 & 0 \\
\hline Women and youth employment - MDG 1 & 3 & 1 & 0 \\
\hline Natural resource protection and conservation - MDG 7 & 2 & 4 & 7 \\
\hline HIV/AIDS orphans - MDG 6 & 2 & 0 & 2 \\
\hline Private sector and/or civil society partnership - MDG 8 & 2 & $1 / 1$ & $1 / 0$ \\
\hline Women's political representation - MDG 3 & 2 & 0 & 7 \\
\hline Governance and minority rights - MDG 6 & 2 & 0 & 0 \\
\hline Access to medicines - MDG 8 & 1 & 0 & 4 \\
\hline Social integration of migrants - MDG 6 & 1 & 0 & 0 \\
\hline Violence against women - MDG 3 & 0 & 1 & 2 \\
\hline
\end{tabular}

PRSPs of 22 countries were analysed with respect to their alignment with the MDG priorities. They are all 'second generation's strategies and reflect some experience with developing these documents. Together they cover a third of all low- and middle-income countries, and include 14 from sub-Saharan Africa, two from Latin America and the Caribbean, two from the Commonwealth of Independent States, three from Asia and one from the Arab States.

\subsection{MDGs and PRSP priorities}

To facilitate analysis and comparison, the 34 MDG Targets and 60 Indicators were grouped into ten priority areas: $:^{5}$ poverty and hunger (MDG 1); employment (MDG 1); education and literacy (MDG 2); gender equality and empowerment of women (MDG 3); health (MDGs 4-6); environment (MDG 7); science and technology (MDG 8); partnership (MDG 8); democracy, good governance and human rights (Millennium Declaration, UN 2000: Ch. 5); social integration of vulnerable groups (Millennium Declaration, UN 2000: Ch. 6). The last two of these ten priorities are not included among the eight MDGs but are key priorities of the UN Development Agenda and the Millennium Declaration. These were in turn subdivided into sub-areas.

The results of the content analysis are summarised in Table 1.

All but four of the 22 PRSPs reviewed emphatically state commitment to the MDGs as a principle (while none mentioned the broader framework of the Millennium Declaration and the IADGs) and almost every one of the key MDG priority areas was included as a priority. However, of the eight Goals, 34 Targets and 60 Indicators, some were emphasised more than others. Some were included as a pillar or a core objective of the PRSP, implementation plans clearly developed, and benchmarks for monitoring progress defined. Others were merely mentioned as an important objective without indication of how they would be implemented.

The five Goals/Targets that were most commonly prioritised were primary schooling, health in general, income poverty, water and sanitation and governance. Governance is not an MDG but 
was a core priority in two-thirds of PRSPs, and refers to economic governance issues of corruption and rule of law rather than democratic governance issues of participation, equity and human rights.

Health is a core priority but the strategies do not all focus on poverty aspects such as maternal health and reproductive rights, or even child survival. Employment is a core priority in nine PRSPs but the action plans focus on reducing unemployment rather than decent work, and work for women and youth. Environmental challenges receive little attention except for water and sanitation. Gender issues focus on education with only two countries having an action plan for political representation and none on violence against women.

All the PRSPs emphasise economic growth as the principal means to achieve the overall objective of reducing poverty. However, few elaborate policies for pro-poor growth, although it is well known that 'trickle-down' approaches are inadequate. The impact of growth on poverty reduction can be very slow unless measures are taken to support sectors such as small-scale agriculture, employment creation, and lagging regions. Social investments can also entrench skewed distribution unless measures are taken to provide basic services or direct them to benefit the more deprived groups. Some of the PRSPs reviewed emphasise pro-poor growth and efforts to accelerate growth in lagging regions while providing protection for vulnerable or marginalised groups (e.g. Tanzania, Uganda, Vietnam) while others (e.g. Yemen, Nicaragua, Madagascar) emphasised economic growth as an objective without differentiating it from reducing poverty, or mentioning agricultural development without emphasis on hunger (e.g. Malawi), implicitly assuming an automatic trickle down.

Inequality as an issue is addressed in reference to regional, rural-urban or gender inequalities. Only one (Bolivia) refers to exclusion of ethnic minorities. Another (Tanzania) identifies equity as an objective in itself.

Equality and non-discrimination are central principles of human rights-based development which are also almost absent in the PRSPs. Ending violence against women as part of the gender equality Goal, and decent work as part of the employment Goal, reproductive rights under maternal health, and equal access under the education Goal. While social integration is mentioned as a priority in more than two-thirds of the PRSPs, and more than half the strategies included some action plans, most addressed issues such as accommodating the handicapped rather than addressing historically entrenched discrimination against racial and cultural groups; specific goals for respect of cultural diversity, minority rights and migrant rights were addressed by just three countries. While governance is a priority in 17 of the 22 PRSPs, only a few (e.g. Tanzania, Senegal) refer to democratic governance and the participation of people in the process of development.

Other priorities that are neglected include technology (Goal 8), partnerships and civil society participation.

\subsection{MDG ambition and PRSP targets}

Global goals are intended to set ambitious Goals and challenge all stakeholders to scale-up effort beyond 'business as usual' (Millennium Project 2005; UNDP 2003).

PRSPs are selective in incorporating 34 targets and 60 indicator targets; more than threequarters of the PRSPs set targets for income poverty, primary schooling, gender equality in primary schooling, maternal mortality, and water and sanitation. But few are set for hunger, employment, child survival, environment, governance, social integration, science and technology and partnership.

As shown in Table 2, most PRSP set targets exceed the ambition of the MDGs as well as historical trends. Perhaps this is because MDG Targets are set to be achieved over 25 years (1990-2015), while many PRSPs aim to achieve the same target in 10-15 years, starting at the MDG year. Among the 22 PRSPs, however, there are a handful which set targets well below the MDG framework, and more disturbingly, below historical trends. These findings are consistent with the earlier analysis of World Bank staff that covers 44 PRSPs (Harrison et al. 2005).

\subsection{MDGs in PRSP process}

Most PRSPs acknowledge the MDGs as a global, normative framework. Most have applied them 


\begin{tabular}{llll} 
Table 2 PRSP targets compared with MDG ambition - percentage of PRSPs reviewed & \\
\hline MDG priority & $\begin{array}{l}\text { Exceeds MDG Targets } \\
\text { (and historical trends) }\end{array}$ & $\begin{array}{l}\text { In line with MDG Targets } \\
\text { (and historical trends) }\end{array}$ & $\begin{array}{l}\text { Falls belou MDG Targets } \\
\text { (and historical trends) }\end{array}$ \\
\hline Income poverty & $80(65)$ & $10(10)$ & $10(20)$ \\
Hunger & $94(42)$ & $0(21)$ & $1(37)$ \\
Primary schooling & $81(42)$ & $5(50)$ & $14(7)$ \\
Gender equality in primary schooling & $100(14)$ & $0(28)$ & $0(56)$ \\
Maternal mortality & $68(71)$ & $5(0)$ & $21(29)$ \\
Reproductive health & $72(78)$ & $1(0)$ & $18(22)$ \\
Child survival & $61(61)$ & $6(6)$ & $33(33)$ \\
HIV/AIDS and other diseases & 43 & 7 & 14 \\
Water and sanitation & $95(88)$ & $5(0)$ & $0(12)$
\end{tabular}

as planning and benchmark tools. Cambodia adapted them to the national context and developed 'Cambodia MDGs'. Others used MDG Targets in combination with other strategic frameworks, such as 'Vision 2025' in Tanzania and 'Vision 2020' in Rwanda. Most, however, appear to have applied MDG Targets somewhat mechanistically, without adaptation.

In many of the countries reviewed, governments with the support of the UN Millennium Project engaged in estimating the cost of investments needed for achieving the MDGs. While these analyses must have provided useful information, they were not reflected in the PRSPs as part of the strategy for scaling-up.

\section{Analysis of donor policies}

Policy documents of 20 bilateral and one multilateral (EU) aid programmes were reviewed. Documents analysed include official statements of policy on development cooperation and MDG reports. As with the PRSPs, documents were coded for content. Since these policy statements do not consistently include indications of resource allocations, and donors do not publish aid allocations by MDG priorities, quantitative analysis of allocation and disbursement priorities could not be undertaken.

\subsection{MDGs and development priorities}

As with the PRSPs, aid policy statements of major bilateral donors align with the MDG

Table 3 Most commonly selected priorities (number of donor programmes)

\begin{tabular}{lll}
\hline & Core priority & Important but not included as core priority \\
\hline Environment - general & 19 & \\
Human rights & 17 & \\
Education - general & 15 & 1 \\
Governance & 15 & 4 \\
Peace and security & 15 & \\
Health - general & 14 & 1 \\
Democracy & 14 & 1 \\
Income poverty & 13 & \\
HIV/AIDS and global diseases & 12 & 1 \\
Countries with special needs (Africa) & 12 & 10 \\
Water and sanitation & 12 & \\
\hline
\end{tabular}


priorities only partially and in varying ways. Those most commonly included are listed in Table 3. This list includes peace and security, which is not an MDG but a core Millennium Declaration objective.

While multidimensional poverty - including income poverty, education and health - is the stated central policy objective of almost all the bilateral aid programmes, some objectives such as maternal mortality and child survival receive surprisingly limited emphasis.

There are also some contrasts with recipient priorities:

- Environment and governance are top priorities for more than three-quarters of the donors reviewed. Unlike the PRSPs, environmental sustainability strategies do not focus on water and sanitation, but on environmental protection and conservation with the more recent statements mentioning climate change. Similarly, governance goes beyond the focus on the rule of law to include human rights and democracy.

- Promoting peace and security is another strategic priority for more than three-quarters of donors. Historically, peace and security have not been part of the 'development' agenda of bilateral donor governments, but there is a strong case for bringing these objectives into this agenda, given that poverty and violent conflict are interrelated.

- MDG priorities that are consistently neglected include employment, hunger, maternal mortality, child survival, gender equality, social integration, and science and technology.

The principles of equality, partnership and global solidarity are included in about half of the donor policy statements, more consistently than in the recipient PRSPs. As in the PRSPs, there is strong emphasis on growth as the principal means to reducing poverty without much attention to the distribution of benefits, creation of employment and other pro-poor concerns.

\subsection{Goal 8 commitments}

One of the most significant achievements of the MDG process was Goal 8, to 'strengthen partnership', or action by the international community and donor countries alongside efforts of the developing country governments to end global poverty. These MDG Goal 8 agendas do not receive much attention in the donor policy statements reviewed; less than half of them mention the international systemic reforms in trade, aid, debt and technology. However, the MDG reports elaborate further on these issues, although not surprisingly reiterating wellestablished positions on global negotiations; support for the Doha development round agendas to expand developing country integration in world trade and aid for trade, support for the Heavily Indebted Poor Country Initiative (HIPG) debt relief initiative, and the Paris declaration on aid effectiveness. Half of the countries report their support for enhancing access to technology but in most cases without much explanation of a specific action taken.

There are some interesting exceptions to this pattern, where policy statements include positions to push the agenda further beyond the established positions; Denmark and Ireland advocate stronger debt relief provisions beyond HIPC; the Netherlands and Sweden include policy support for expanding access to essential medicines through the use of compulsory licensing provisions of TRIPS.

MDGs are consistently used as long-term objectives that define a global development strategy based on which donor agendas emphasise poverty reduction and its human dimensions. There was little evidence that aid donors use MDG Targets as planning targets: a framework for allocating resources in their country programmes. On the other hand, recent trends in overall aid allocations from the Development Assistance Committee (DAG) of the Organisation of Economic Co-operation and Development (OECD) donor countries show a trend to increasing allocation to the social sectors (UNGTAD 2008), which no doubt reflects commitment to the MDGs. However, it is not clear if this means resource allocation to the priorities within the social sectors most directly relevant to the MDG Targets. This requires further analysis. Moreover, the increase in social sector allocations has also meant a decrease in support to the productive and economic sectors. Such support is necessary to sustain economic growth to generate domestic resources to finance social investments. 


\section{Conclusions}

Do donor and developing country governments have 'ownership' of the MDGs and are they being implemented? This study has found a high degree of commitment to MDGs as a whole but both PRSPs and donors are selectively implementing some and not all MDG priorities. The key issue is not whether there is ownership of MDGs as such but how this is interpreted, which of the MDG priorities are being implemented, and what policy strategies are being adopted.

The strategy in the majority of the PRSPs focus on economic growth and investment in the social sectors and reflect an assumption that 'trickledown' would achieve the poverty reduction objectives of the MDG agenda. Most did not contain a strategy for 'pro-poor growth' and pro-poor social investments. Nor do they contain strategies of building democratic governance creating an environment to empower the poor and addressing institutionalised obstacles to their participation in economic, social and political life.

The growth and social investment approach, reminiscent of the $1980 \mathrm{~s}$, ignores much that has been learned during the 1990s about the multidimensional nature of poverty and the important role of empowerment and participation as strategies for poverty reduction. The 2000 World Development Report (World Bank 2000), for example, notes that while labourintensive growth, social protection and social investments are necessary for poverty reduction, they are not sufficient. It then goes on to expand the strategy by proposing opportunity, empowerment and security as pillars of an effective poverty reduction strategy.

Neither the PRSPs nor donor policy statements explore the partnership efforts required to remove the constraints to poverty reduction posed by the global market environment and initiatives required to move the trade and aid agendas forward. MDGs and PRSPs are not the principle mechanisms for these agendas, since trade issues are being debated in the context of Doha Round negotiations and World Trade Organization (WTO) processes while aid issues are being discussed in the OECD DAC and in the recently launched Development Cooperation Forum of the UN Economic and Social Council (ECOSOC). Nonetheless, defining stronger quantitative Indicators under Goal 8 could help pressure these other fora.

The PRSPs and the donor statements focus on the MDGs and use them as long-term objectives. The donor statements do not use the MDGs as planning targets. The PRSPs attempt to use the MDGs as planning targets mostly in a mechanistic fashion by applying the quantitative targets without adaptation.

\section{Implementing the MDGs or the Millennium Declaration?}

This article began with a reminder that MDGs are 'Indicators' of progress in implementing the objectives of the Millennium Declaration. The Declaration and the UN conferences from which it emerged sought an agenda for a more inclusive globalisation where the benefits would be more widely shared, and rooted in the ethical values of global solidarity and equality. The agenda was therefore to redress the increasing inequality between and within countries resulting from liberalisation and economic globalisation. Just as empowerment of poor people is a core strategy for removing obstacles to equal opportunities, reform of global economic institutions to create a more level playing field was central to integrating marginalised countries into the global economy.

Most PRSPs are aligned with the MDG priorities but reflect little of the core Millennium Declaration objectives and the UN Development Agenda. The PRSPs implement social investments but not the rest of the inclusive globalisation agenda while they implement the Washington Consensus macroeconomic policy agendas of macroeconomic stability, liberalisation and institutional reforms. This is not surprising, given that PRSPs are necessary for accessing debt relief provisions under HIPC, and International Monetary Fund (IMF) loans under the Poverty Reduction and Growth Facility (PRGF).

MDGs are embedded in a new architecture of development aid that has shifted some instruments but maintained the neoliberal economic strategy intact. Under this new architecture, poverty reduction MDGs define the long-term objective, the PRSPs define the nationally owned strategy to this end; while partnership and mutual accountability define the donor-recipient relationship. This is a major move away from the architecture of the earlier 
decades dominated by economic stabilisation and growth as an objective, Policy Framework Paper and Public Investment Programmes as a strategy, and conditionality as the relationship. But the fundamental policy approach of neoliberalism continues to be applied, while incorporating social investments to meet basic needs as an important addition. More fundamental changes in institutions and norms are not accommodated.

The PRSPs are aligned with MDGs but not the Millennium Declaration and reflect a continuation of the neoliberal agenda of the 1980s and the 1990s. The PRSPs are required for accessing debt relief provision under the HIPC programme and loans under the IMF Poverty Reduction and Growth Facility (PRGF). These programmes follow the same macroeconomic policy prescriptions of the Washington Consensus as did the Structural Adjustment Programmes of the 1980s and 1990s.

\subsection{After 2015: recasting the MDGs}

To better align international development to the core objective of the Millennium Declaration, the MDGs need to be refocused to implement a human rights-based approach. First, as an instrument, local adaptation of targets and processes should be promoted so that they could be effective not only as long-term objectives but as planning instruments. Second, as policy

\section{Notes}

* I am grateful to Maximillian Ashwill and Patrick Guyer for excellent research support. I am solely responsible for all errors and omissions. This article is based on FukudaParr (2008).

1 UNDP About MDGs: The Basics, http://www.undp.org/mdg/basics.shtml (accessed 12 July 2009).

2 See Fukuda-Parr and Hulme (2009) for a discussion of this historical context and the agendas, they need to focus on pro-poor growth and democratic governance at the national level and systemic reforms in global governance.

Finally, as Indicators of the complex objectives of the Millennium Declaration, MDGs need to include a Goal on reducing inequality within and between countries.

This can be readily done since quantitative measures are available. Income inequalities are measured by the Gini coefficient or the ratio of income shares of top and bottom quintiles of population. Other gaps can be measured by a number of social Indicators such as life expectancy or under-fives mortality.

The history of goal setting as a means to promote neglected development priorities dates back to the 1960s. Since then, there have been recurring debates about their effectiveness but as Richard Jolly et al. (2004) show, there have been more success stories than is often recognised. Quantitative goals have helped focus attention on critical areas for action and have brought more rigour to evaluating development progress. The MDGs are unprecedented in their impact on mobilising awareness and consensus on poverty as an ethical challenge of the twentyfirst century. The challenge for after 2015 is to mobilise the MDGs for inclusive globalisation.

emergence of the poverty norm. Jolly et al. (2004) reviews the evolution in terms of UN history.

3 See Fukuda-Parr and Hulme (2009) for a historical account of this process.

4 Second strategy prepared in a given country.

5 The MDG Targets and Indicators are too numerous and do not overlap with most PRSP sectoral categories.

de Renzio, Paolo (2005) 'Scaling up Versus Absorptive Capacity: Challenges and Opportunities for Reaching the MDGs in Africa', ODI Briefing Paper, May, London: Overseas Development Institute

Easterly, William (2006) 'Reliving the 50s: The Big Push, Poverty Traps, and Takeoffs in Economic Development', Journal of Economic Growth 11.4: 289-318 735-51 
Fukuda-Parr, S. (2008) Are the MDGs Priority in Development Strategies and Aid Programmes? Only Few Are!, IPG Working Paper 48, Brasilia: UNDP International Poverty Centre

Fukuda-Parr, Sakiko and Hulme, David (2009) International Norm Dynamics and 'The End of Poverty': Understanding the Millennium Development Goals (MDGs), Brooks World Poverty Institute Working Paper 96, www.bwpi.manchester.ac.uk/resources/Working -Papers/bwpi-wp-9609.pdf (accessed 12 November 2009)

Gupta, Sanjeev; Powell, Robert and Yan, Yongzheng (2005) The Macroeconomic Challenges of Scaling Up Aid to Africa, IMF Working Paper WP/05/179, Washington DC: International Monetary Fund

Harrison, Machiko; Klugman, J. and Swanson, Eric (2005) 'Are Poverty Reduction Strategies Undercutting the Millennium Development Goals? An Empirical Review', mimeo, World Bank

Jolly, Richard; Emmerij, Louis; Ghai, Dharam and Lapeyre, Frederic (2004) UN Contributions to Development Thinking and Practice, Bloomington: Indiana University Press

Martin, Matthew and Stever, Jonathan (2007) Key Challenges Facing Global Development Cooperation, discussion paper prepared for UN DESA, Development Cooperation Forum Launch, www.un.org/ecosoc/newfunct/ dcflaunch.shtml (accessed March 2008)

Millennium Project (2005) Investing in Development, London: Earthscan

Nelson, Paul J. (2007) 'Human Rights, the Millennium Development Goals and the Future of Development Cooperation', World Development 35.12: 2041-55
OHCHR (2008) Claiming the MDGs: A Human Rights Approach, Geneva and New York: United Nations (Office of the High Commissioner for Human Rights)

Roy, Rathin and Heurty, A. (2005) 'Investing in Development: The Millennium Development Goals, Aid and Sustainable Capital Accumulation', Journal of International Affairs 58.2, Spring: 161-76

Saith, A. (2006) 'From Universal Values to Millennium Development Goals: Lost in Translation', Development and Change 37.5: 1167-99

UN (2001) Road Map Towards the Implementation of the United Nations Millennium Declaration, Report of the Secretary General, 6 September 2001, UN General Assembly, A/56/326

UN (2000) United Nations Millennium Declaration, Resolution adopted by the General Assembly, 18 September 2000, A/RES/55/2

UN DESA (2007) The United Nations Development Agenda: Development for All, New York: United Nations, www.un.org/esa/devagenda/ UNDA_BW5_Final.pdf (accessed 12 November 2009)

UNCTAD (2008) The Least Developed Countries Report, Geneva: UN Publications

UNDP (2003) Human Development Report 2003: Millennium Development Goals, A Compact to End Human Poverty, New York: United Nations Development Programme

World Bank (2008) Global Monitoring Report 2008, Washington DC: World Bank

World Bank (2000) World Development Report 2000/2001 Attacking Poverty: Opportunity, Empowerment, Security, Washington DC: Oxford University Press 